\title{
Baicalin promotes the viability of Schwann cells in vitro by regulating neurotrophic factors
}

\author{
WENPU ZUO ${ }^{1 *}$, HUAYU WU ${ }^{2 *}$, KUN ZHANG $^{3,4}$, PEIZHEN LV ${ }^{3,4}$, \\ FUBEN XU ${ }^{1,5}$, WEIZHE JIANG ${ }^{6}$, LI ZHENG $^{1,5}$ and JINMIN ZHAO ${ }^{3-5}$ \\ ${ }^{1}$ Medical and Scientific Research Center; ${ }^{2}$ Department of Cell Biology and Genetics, School of Premedical Sciences; \\ ${ }^{3}$ Guangxi Key Laboratory of Regenerative Medicine, Guangxi Medical University; ${ }^{4}$ Department of Orthopedic Trauma and \\ Hand Surgery, The First Affiliated Hospital of Guangxi Medical University; ${ }^{5}$ Key Laboratory of Regenerative Medicine of \\ Guangxi High School; ${ }^{6}$ Department of Pharmacology, Guangxi Medical University, Nanning, Guangxi 530021, P.R. China
}

Received January 20, 2016; Accepted February 14, 2017

DOI: $10.3892 /$ etm.2017.4524

\begin{abstract}
The proliferation and migration of Schwann cells (SCs) are key events in the process of peripheral nerve repair. This is required to promote the growth of SCs and is a challenge during the treatment of peripheral nerve injury. Baicalin is a natural herb-derived flavonoid compound, which has been reported to possess neuroprotective effects on rats with permanent brain ischemia and neuronal differentiation of neural stem cells. The association of baicalin with neuroprotection leads to the suggestion that baicalin may exert effects on the growth of SCs. In the present study, the effects of baicalin on SCs of RSC96 were investigated. RSC96 SCs were treated with various concentrations of baicalin $(0,5$, 10 or $20 \mu \mathrm{M}$ ) for 2, 4 and 6 days. Cell attachment, viability and gene expression were monitored via the MTT assay and reverse transcription-quantitative polymerase chain reaction. The gene expression levels of several neurotrophic factors, such as glial cell-derived neurotrophic factor, brain-derived neurotrophic factor and ciliary neurotrophic factor, which are considered important factors in the process of never cell regeneration, were detected. The results indicated that baicalin was able to promote the viability of RSC96 SCs in a dose-dependent manner and the concentration of $20 \mu \mathrm{M}$
\end{abstract}

Correspondence to: Dr Weizhe Jiang, Department of Pharmacology, Guangxi Medical University, 22 Shuangyong Road, Nanning, Guangxi 530021, P.R. China

E-mail: jiangweizhe6812@163.com

Dr Li Zheng, Medical and Scientific Research Center, Guangxi Medical University, 22 Shuangyong Road, Nanning, Guangxi 530021, P.R. China

E-mail: zhengli224@163.com

*Contributed equally

Key words: baicalin, proliferation, Schwann cell, RSC96, glial cell-derived neurotrophic factor, brain-derived neurotrophic factor, ciliary neurotrophic factor of baicalin exhibited the greatest cell viability and gene expression of the studied neurotrophic factors. The present findings suggested that baicalin likely affects SCs metabolism, through modulating the expression of neurotrophic factors. To conclude, the present study indicates that baicalin may be potential therapeutic agent for treating peripheral nerve regeneration.

\section{Introduction}

Peripheral nerve injuries occur with a high frequency, accounting for up to $3 \%$ of all trauma injuries $(1,2)$. In the majority of cases, surgical intervention is necessary due to the self-regenerative capability of nerves; however, this is time-consuming and incomplete, as described in (3), which may cause functional impairment. Although autograft transplantation is the first choice of treatment, the shortage of donor resources and the repercussions of this invasive treatment to the donor present as major limitations $(4,5)$. However, the discovery of an alternative therapy to replace autografts and treat peripheral nerve injury has presented as a challenge.

Among the typical approaches for treating nerve crush injury, Schwann cell (SC)-based therapy is highly recommended (6). SCs, the principle glia in the peripheral nervous system, have an important role in the development, function and regeneration of peripheral nerves (7). Following peripheral nerve injury, SCs aid in phagocytizing the damaged end of the axon and provide physical support to regenerate axons by forming 'Bands of Büngner'. Furthermore, SCs create a suitable axonal growth environment by producing neurotrophic factors, such as brain-derived neurotrophic factor (BDNF), glial cell-derived neurotrophic factor (GDNF), ciliary neurotrophic factor (CNTF) and neurotrophic factors-3, $-4 / 5$ and -6 (NT-3, NT-4/5, and NT-6, respectively) (8-12). However, the slow growth rate of SCs is reported to be one of the major limitations of SC application in regenerative medicine (13). In addition, elevating the proliferation ability of SCs is important for constructing tissue-engineered nerves (6). As a result, researchers have been exploring various promoting agents for SCs proliferation, such as interleukin-1 $\beta$ (14) and tanshinone IIA (15). 
Utilizing plant-derived traditional Chinese medicines to treat various types of diseases has a long history in East Asian countries, such as China, Korea and Japan (16). Furthermore, some western medicines are derived from major constituent of traditional Chinese medicine (17) Scutellaria baicalensis Georgi (Huangqin in Chinese), a traditional Chinese medicine, has been used to treat inflammation, fever, ulcers and cancer for hundreds of years (18-20) and a recent study has reported that flavonoids from the stems and leaves of $S$. baicalensis Georgi have neuroprotective effects (21). Baicalin, one of the major flavonoid isolated from the root of S. baicalensis, has a variety of biological functions, including anti-inflammatory, anti-oxidant and anti-apoptotic activities (22-24). Previous studies have revealed that baicalin had neuroprotective effects on permanent brain ischemia in rats (25) and was able to promote the neuronal differentiation of neural stem cells $(26,27)$. However, little is known on whether baicalin is capable of exerting positive or negative effects on SC proliferation and differentiation. The present study aimed to investigate the effects of different concentrations of baicalin on the viability of RSC96 SCs. The results revealed that baicalin was able to promote the viability of RSC96 SCs at a particular concentration.

\section{Materials and methods}

Cell culture. RSC96 SCs were purchased from China Center for Type Culture Collection (Wuhan, China) and cultured in Dulbecco's modified Eagle medium (DMEM)-F12 (1:1; Thermo Fisher Scientific, Inc., Waltham, MA, USA) supplemented with $10 \%$ fetal bovine serum (Hangzhou Sijiqing Biological Engineering Materials Co., Ltd., Hangzhou, China) and $1 \%$ of penicillin/streptomycin in an incubator at $37^{\circ} \mathrm{C}$ with $95 \%$ air and $5 \% \mathrm{CO}_{2}$. Baicalin (Chengdu Best-Reagent Chemical, Co., Ltd., Chengdu, China) was dissolved in $0.2 \%$ dimethyl sulfoxide (DMSO) and prepared as a stock solution with a final concentration of $100 \mathrm{mM}$ and stored at $-20^{\circ} \mathrm{C}$. The stock solution was diluted with culture medium immediately prior to treatment.

Cytotoxicity assay. To determine the level of cytotoxicity of baicalin on RSC96 SCs, cell cytotoxicity was detected with a MTT assay (Gibco; Thermo Fisher Scientific, Inc.) method. RSC96 SCs were seeded in 96-well plates at a density of 1,000 cells/well and the cell viability was determined by using the MTT assay on day 3. Following treatment with various concentrations of baicalin ( 0 to $1,000 \mu \mathrm{M}$ where $0 \mu \mathrm{M}$ was used as a control) for 3 days, $20 \mu \mathrm{l}$ MTT ( $5 \mathrm{mg} / \mathrm{ml})$ was added to each well and plates were incubated in the dark at $37^{\circ} \mathrm{C}$ for $4 \mathrm{~h}$. Once MTT was removed, cells were treated with $200 \mu \mathrm{l}$ DMSO (Amresco, LLC, Solon, OH, USA) for crystal solubilization. The spectrometric absorbance at $570 \mathrm{~nm}$ was read using Multiskan ${ }^{\text {TM }}$ GO microplate spectrophotometer (Thermo Fisher Scientific, Inc., USA).

Measure of cell viability via the MTT assay. RSC96 SCs were seeded in 96-well plates at a density of 1,000 cells/well and the cell viability was determined by using the MTT assay on days 2,4 , and 6 . Once cells were treated with various concentration of baicalin $(5,10$ and $20 \mu \mathrm{M})$, MTT solution $(5 \mathrm{mg} / \mathrm{ml})$ was added and the cells were incubated for $4 \mathrm{~h}$ at $37^{\circ} \mathrm{C}$. Following removal of the incubation medium, the dark blue formazan crystals formed in the intact cells and all samples were solubilized with $200 \mu \mathrm{l}$ DMSO. Subsequently, the absorbance was measured at $570 \mathrm{~nm}$ on a microplate spectrophotometer (Thermo Fisher Scientific, Inc.).

Measure of cell viability via fluorescein diacetate staining. Live RSC96 SCs were examined using fluorescein diacetate (FDA) on days 2, 4 and 6. A stock solution of FDA (Sigma-Aldrich; Merck Millipore, Darmstadt, Germany) was prepared by dissolving $5 \mathrm{mg}$ FDA in $1 \mathrm{ml}$ acetone. Staining solution was prepared by mixing $5 \mathrm{ml}$ PBS with $8 \mu 1$ FDA stock solution. Once the culture medium was removed, $0.5 \mathrm{ml}$ staining solution was added and the cells were stained in the dark for $5 \mathrm{~min}$. The evaluation of viability was conducted by fluorescent microscopy (magnification, x100, Nikon Corporation. Tokyo, Japan). ImageJ software (version 1.48v; National Institutes of Health, Bethesda, MA, USA) was used for quantitative analysis of the fluorescein diacetate stained cells.

Hematoxylin and eosin staining. RSC96 SCs were grown at $1 \times 10^{5}$ cells/ml in DMEM/F12 (1:1) with $0,5,10$ or $20 \mu \mathrm{M}$ of baicalin for 2, 4, and 6 days on a 24-well plate with a coverslip set at the bottom. Following fixing in $95 \%$ ethanol for 20 min, the coverslip contents were washed in PBS twice, immersed in hematoxylin for $2 \mathrm{~min}$, and washed in water for 1 to $3 \mathrm{sec}$ to remove hematoxylin. The coverslip was washed in $1 \%$ hydrochloric acid and ethanol for 2 to $3 \mathrm{sec}$, water for $10 \mathrm{sec}$, ammonia for $15 \mathrm{sec}$ and running water for $10 \mathrm{sec}$. Eosin staining was performed for $1 \mathrm{~min}$ and the stain was removed by washing with water for $2 \mathrm{sec}, 80 \%$ ethanol for $2 \mathrm{sec}, 95 \%$ ethanol for $5 \mathrm{~min}$ and $100 \%$ ethanol for $10 \mathrm{~min}$. Subsequently, the coverslip was air-dried and mounted with neutral gum for light microscopy analysis. Images of five random fields of the culture were captured (magnification, x100).

Reverse transcription-quantitative polymerase chain reaction (RT-qPCR). Total RNA was extracted from RSC96 SCs using TRIzol reagent (Invitrogen; Thermo Fisher Scientific, Inc.), following the manufacturer's instructions. cDNA was synthesized from reverse transcribed total RNA using a PrimeScript RT reagent kit with gDNA Eraser (Takara Biotechnology Co., Ltd., Dalian, China). Briefly, residual DNA was removed as follows: $10 \mu \mathrm{l}$ total volume of $2 \mu \mathrm{l} 5 \mathrm{x}$ gDNA eraser buffer, $1 \mu \mathrm{g}$ total RNA, $1 \mu \mathrm{lgDNA}$ eraser and RNase-free $\mathrm{dH}_{2} \mathrm{O}$ at $42^{\circ} \mathrm{C}$ for 2 min. For reverse transcription, $20 \mu 1$ total volume was used with $10 \mu 1$ of the reaction solution as described, $4 \mu 1$ 5x PrimeScript buffer 2, $1 \mu 1$ PrimeScript RT enzyme mix I, $1 \mu 1 \mathrm{RT}$ primer mix and $4 \mu 1$ RNase-free $\mathrm{dH}_{2} \mathrm{O}$. This reaction was performed at $37^{\circ} \mathrm{C}$ for $15 \mathrm{~min}$, followed by incubation in an $85^{\circ} \mathrm{C}$ water bath for $5 \mathrm{sec}$. The synthesized cDNA was cooled at $4^{\circ} \mathrm{C}$ for 5 min and then stored at $-20^{\circ} \mathrm{C}$ until real-time quantitative PCR reactions. PCR was performed on Mastercycler ${ }^{\circledR}$ ep realplex 4 system (Eppendorf, Hamburg, Germany) using FastStart Universal SYBR Green Master (Roche Diagnostics, Indianapolis, IN, USA) according to the manufacturer's protocol. Briefly, a total reaction volume of $20 \mu \mathrm{l}$ was used containing $10 \mu \mathrm{l}$ SYBR Master Mix, $0.4 \mu \mathrm{l}$ each primer $(0.4 \mu \mathrm{mol} / \mathrm{l}), 2 \mu \mathrm{l} \mathrm{cDNA}$, and $7.6 \mu \mathrm{l}$ RNase-free $\mathrm{dH}_{2} \mathrm{O}$. The cycling conditions were as follows, for 35 cycles: 
Denaturing, at $94^{\circ} \mathrm{C}$ for $30 \mathrm{sec}$, annealing at $54^{\circ} \mathrm{C}$ for $30 \mathrm{sec}$ and extension at $72^{\circ} \mathrm{C}$ for $30 \mathrm{sec}$. A final melting curve analysis was performed utilizing conditions of $95^{\circ} \mathrm{C}$ for $15 \mathrm{sec}, 60^{\circ} \mathrm{C}$ for $60 \mathrm{sec}$, followed by $95^{\circ} \mathrm{C}$ for $15 \mathrm{sec}$. The PCR products for glial cell-derived neurotrophic factor (GDNF), BDNF and ciliary neurotrophic factor (CNTF) were 129, 182 and $191 \mathrm{bp}$, respectively. The primer sequences are indicated in Table I. All reactions were performed in triplicate. The relative expression levels of mRNA were calculated using the comparative $2^{-\Delta \Delta \mathrm{Cq}}$ method (28) and normalized against GAPDH.

Immunohistochemistry. RSC96 SCs were fixed in 95\% ethanol for $20 \mathrm{~min}$ and washed in PBS twice. Cells were incubated in $\mathrm{H}_{2} \mathrm{O}_{2}(3 \%)$ for 10 min to block peroxidase and rinsed using distilled water. Sections were subsequently washed with PBS three times for 2 min. Rabbit anti-rat S100B antibody (1:200; catalogue no. BA0120; Wuhan Boster Biological Technology, Ltd., Wuhan, China) was added and incubated at room temperature for $2 \mathrm{~h}$ and subsequently rinsed with PBS, containing $0.05 \%$ Tween-20, three times for $2 \mathrm{~min}$. Slides were incubated with peroxidase-conjugated goat anti-rabbit IgG (1:100; catalogue no. SP-9001; Zhongshan Jin Qiao Biotechnology Co., Beijing, China) for $30 \mathrm{~min}$ at $37^{\circ} \mathrm{C}$. Following incubation, sections were washed with PBS, containing $0.05 \%$ Tween-20, three times for $2 \mathrm{~min}$. Diaminobenzidine was added to visualize primary antibody staining and samples were washed in distilled water. Subsequently, slides were counterstained with hematoxylin for $20 \mathrm{sec}$, washed once in water, mounted, dried and dehydrated by immersing in $70 \%$ ethanol for $10 \mathrm{~min}, 95 \%$ ethanol for $10 \mathrm{~min}$ and $100 \%$ ethanol for $10 \mathrm{~min}$. Following dehydration, the mounted slides were observed by using a Nikon light microscope at a magnification, x100).

Statistical analysis. Data were statistically analyzed using the SPSS software package, version 17.0 (SPSS, Inc., Chicago, IL, USA). Statistical analysis among multiple samples was performed by one-way analysis of variance followed by post hoc least significant difference (LSD) tests. $\mathrm{P}<0.05$ was considered to indicate a statistically significant difference.

\section{Results}

Cytotoxicity of baicalin. The cytotoxicity of baicalin on RSC96 SCs was examined by MTT assay. RSC96 SCs were treated with baicalin at increasing concentrations $(0.1$ to $1,000 \mu \mathrm{M})$. Minimal cytotoxic effects were observed when RSC96 SCs were treated with baicalin for 3 days at doses $0.1,0.5,1,5$ or $10 \mu \mathrm{M}$ (Fig. 1). However, significant cytotoxic effects were observed in cells treated with $>50 \mu \mathrm{M}$, indicated by the significantly reduce viability exhibited by the SCs ( $\mathrm{P}<0.001$ vs. $0 \mu \mathrm{M}$; Fig. 1). Therefore, concentrations of 5, 10 or $20 \mu \mathrm{M}$ of baicalin were selected for subsequent investigations.

Cell viability. The cell viability of RSC96 SCs was explored using the MTT assay in the present study. The viability of SCs was indicated to be time- and dose-dependent (Fig. 2). Furthermore, SCs were more viable when incubated with various concentrations of baicalin $(0,5,10$ or $20 \mu \mathrm{M})$ when compared with the control at different time points. Cell



Figure 1. Cytotoxicity analysis of RSC96 Schwann cells treated with differen concentrations of baicalin $(0$ to $1,000 \mu \mathrm{M})$ for 3 days (mean \pm standard deviation; $\mathrm{n}=5)$. ${ }^{*} \mathrm{P}<0.05 ;{ }^{* *} \mathrm{P}<0.01 ;{ }^{* * * *} \mathrm{P}<0.001$ vs. the control group.



Figure 2. Proliferative effects of baicalin on RSC96 SCs. SCs were incubated with 0 (control), 5, 10 or $20 \mu \mathrm{M}$ of baicalin for 2, 4 and 6 days. Cell viability was measured by MTT assay. ${ }^{*} \mathrm{P}<0.05,{ }^{* *} \mathrm{P}<0.01$ vs. the control group. ${ }^{\#} \mathrm{P}<0.05$ between the indicated experimental groups. Data are presented as the mean \pm standard deviation $(n=3)$. SC, schwann cells.

viability following treatment of baicalin $(20 \mu \mathrm{M})$ significantly increased up to $\sim 15 \%$ when compared with the control on day 2 (P<0.05; Fig. 2). In all groups of SCs treated with baicalin, $20 \mu \mathrm{M}$ of baicalin was the optimal concentration that promoted the highest cell viability of RSC96 SCs.

To further investigate the effects of baicalin on RSC96 SC viability, the live viability of RSC96 SCs was analyzed by FDA staining. As shown in Fig. 3, the number of viable cells, which were green in color, increased with time in all groups. In agreement with the MTT analysis, a greater number of viable cells were presented in baicalin-treated groups when compared with the control at different corresponding culture times. These data support the beneficial effect of baicalin on SC survival. In all baicalin groups, the number of viable cells was highest when incubated in medium with $20 \mu \mathrm{M}$ baicalin (Fig. 4). 
Table I. Genes and oligonucleotide primers used in PCR analysis.

\begin{tabular}{llcc}
\hline Gene & \multicolumn{1}{c}{ Primer sequence (5' to 3') } & Length (bp) & Amplicon size (bp) \\
\hline GDNF & F: AGACCGGATCCGAGGTGC & 18 & 129 \\
& R: TCGAGAAGCCTCTTACCGGC & 20 & 182 \\
BDNF & F: TACCTGGATGCCGCAAACAT & 20 & 191 \\
& R: TGGCCTTTTGATACCGGGAC & 20 & \\
CNTF & F: ATGGCTTTCGCAGAGCAAAC & 20 & 99 \\
& R: CAACGATCAGTGCTTGCCAC & 20 & 20 \\
\end{tabular}

PCR, polymerase chain reaction; GDNF, glial cell-derived neurotrophic factor; BDNF, brain-derived neurotrophic factor; CNTF, ciliary neurotrophic factor; F, forward primer; R, reverse primer.
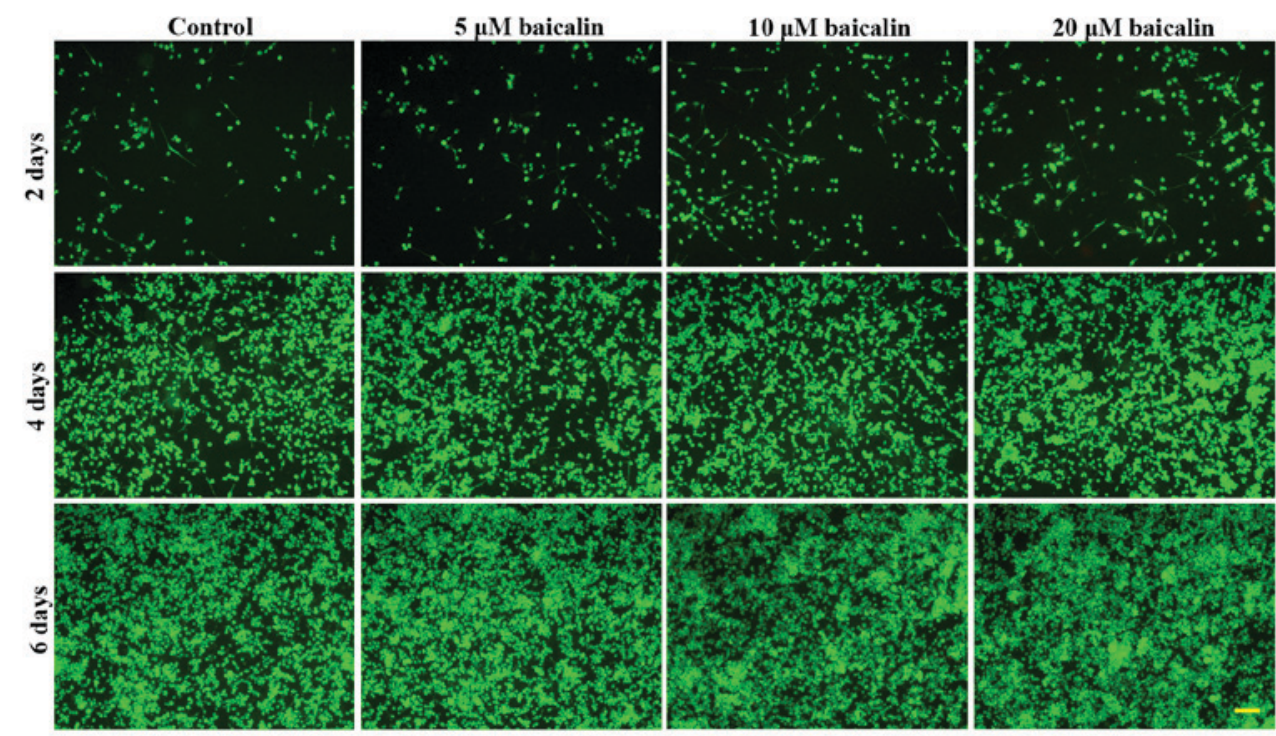

Figure 3. Cell viability was measured by fluorescein diacetate staining under a light microscope. RSC96 Schwann cells were incubated with 0 (control), 5,10 or $20 \mu \mathrm{M}$ of baicalin for 2, 4 and 6 days (magnification x100; scale bar, $200 \mu \mathrm{m}$ ).

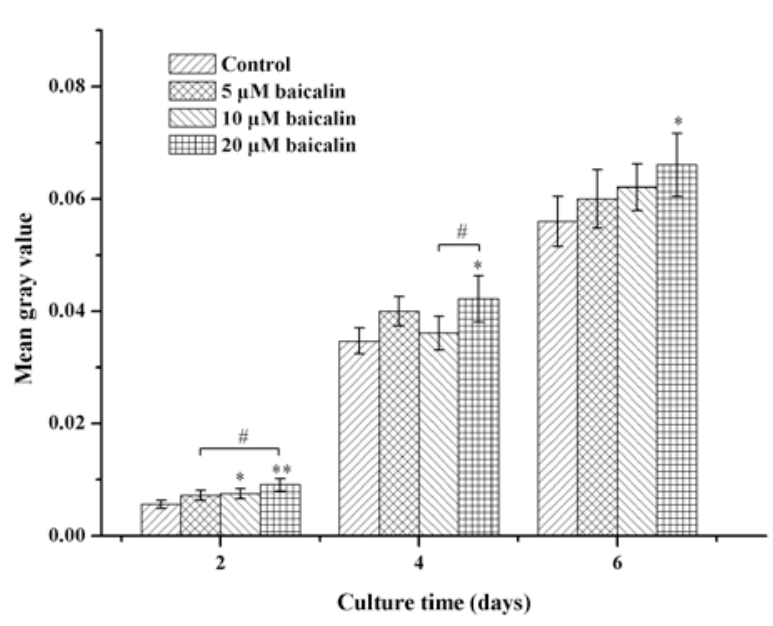

Figure 4. Quantitative analysis of the fluorescein diacetate stained cells, derived from ImageJ software. The mean gray value was obtained by integrated density divided by the area. ${ }^{*} \mathrm{P}<0.05,{ }^{* * *} \mathrm{P}<0.01$ vs. the control group. ${ }^{\#} \mathrm{P}<0.05$ between the indicated experimental groups.
Cell morphology. Hematoxylin and eosin staining was used to observe RSC96 SC morphology. Dendrites, the typical component of nerve cells, were clearly observed under the microscope following 2 days of culture; however, over time, the number of cells with dendrites decreased whereas the number of rounded cells increased. As showed in Fig. 5, the SCs grew slower in control when compared with the groups treated with baicalin at 2,4 and 6 days. Furthermore, among the three concentrations, the present data suggests that $20 \mu \mathrm{M}$ of baicalin stimulated cell proliferation the most prominently.

Gene expression. The effect of $0,5,10$ or $20 \mu \mathrm{M}$ of baicalin on RSC96 SCs was further investigated by detecting the gene expression of the important neurotrophic factors, GDNF, BDNF and CNTF. The expression levels of these genes were examined at 2, 4 and 6 days. Gene expression levels of GDNF, BDNF and CNTF were markedly increased in all baicalin-treated RSC96 SCs and significantly increased in RSC96 SCs treated with $20 \mu \mathrm{M}$ baicalin when compared with the control $(\mathrm{P}<0.01)$, 


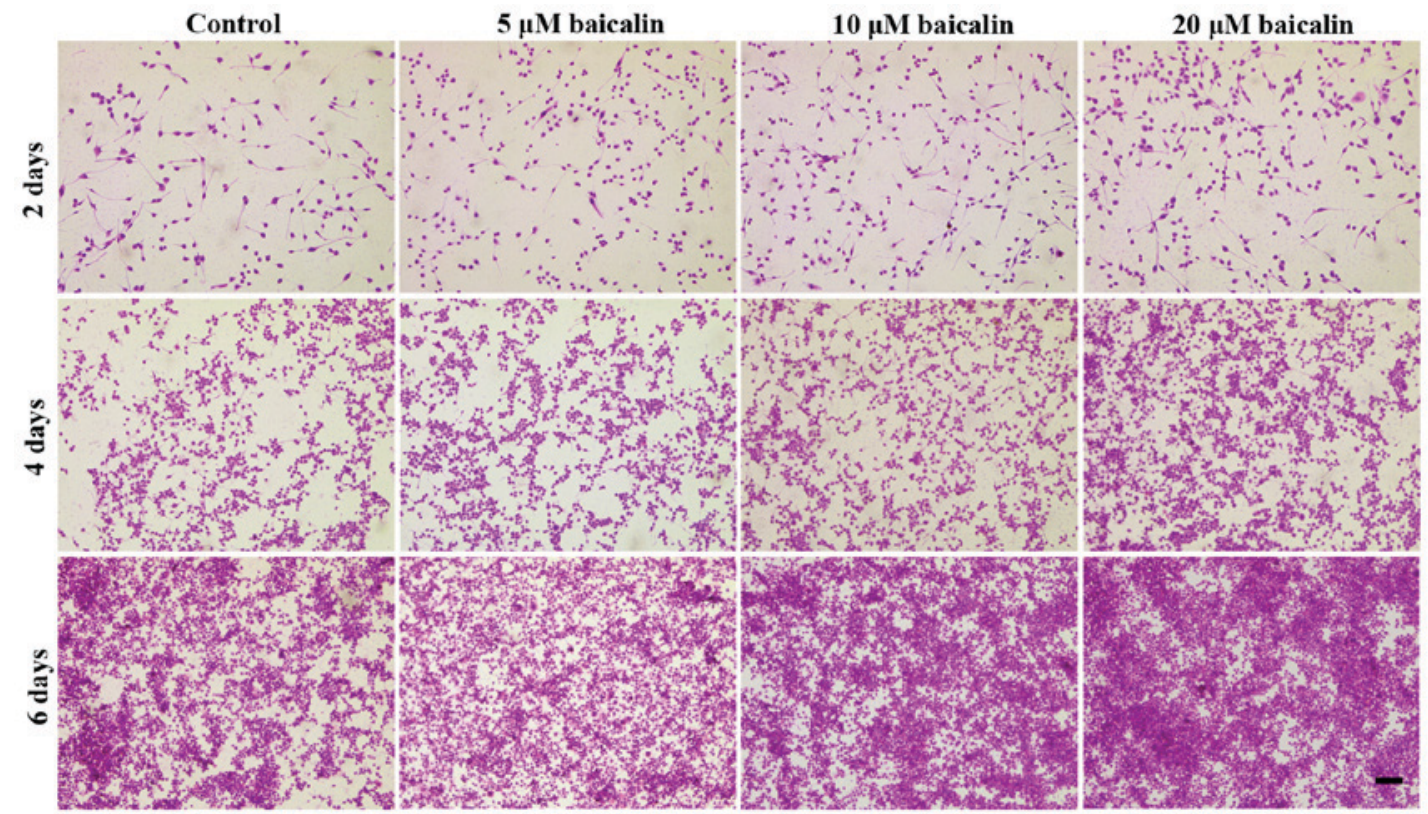

Figure 5. Hematoxylin-eosin staining images showing the morphology of RSC96 SCs cultured in vitro with 0 (control), 5, 10 or $20 \mu \mathrm{M}$ of baicalin for 2, 4 and 6 days (magnification x100; scale bar, $200 \mu \mathrm{m}$ ).

A

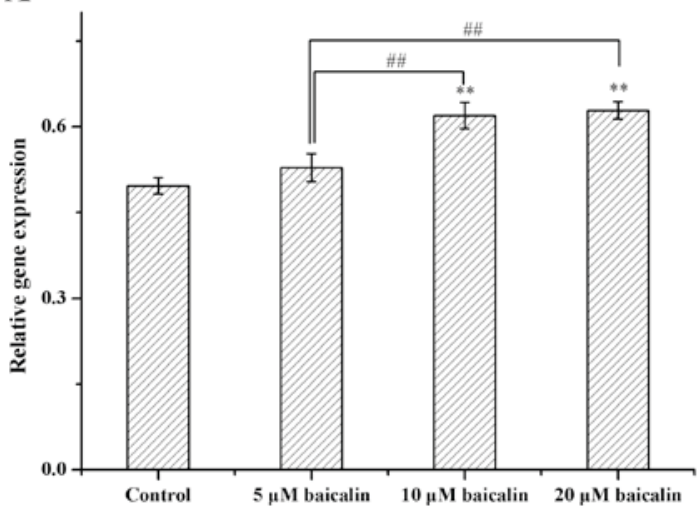

C

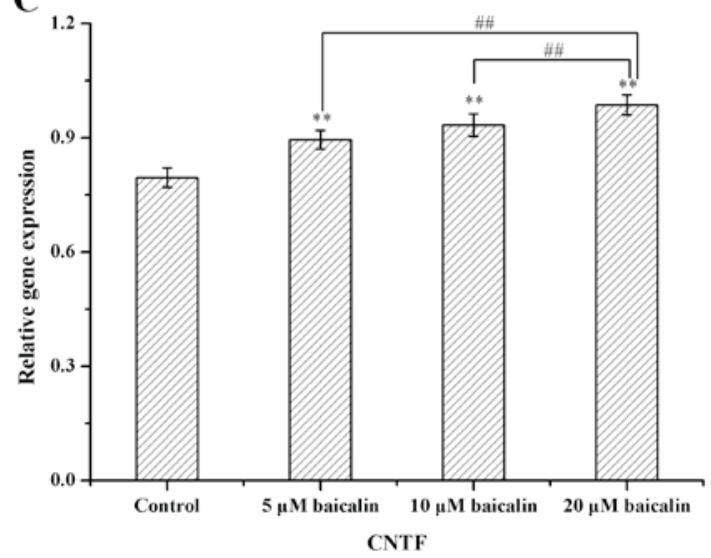

B

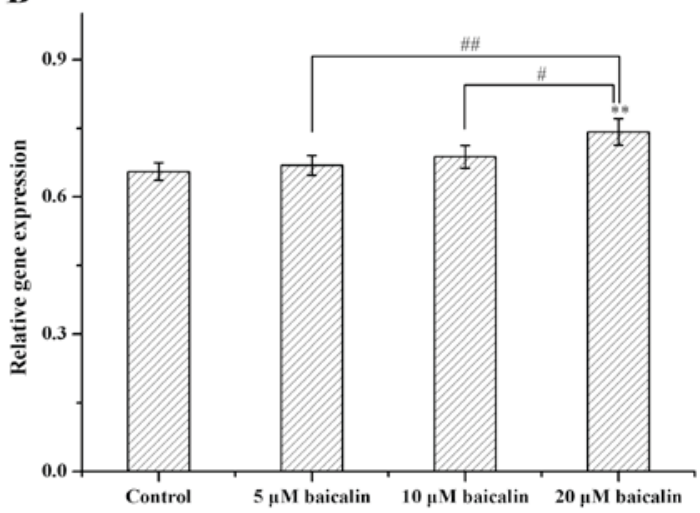

Figure 6. Gene expression analysis of the neurotrophic factors, (A) GDNF, (B) BDNF and (C) CNTF by reverse transcription-quantitative polymerase chain reaction. RSC96 Schwann cells were cultured with 0 (control), 5, 10 or $20 \mu \mathrm{M}$ of baicalin for 4 days. The gene expression levels were analyzed by the $2^{-\Delta \Delta C q}$ method using GAPDH as the internal control. ${ }^{* *} \mathrm{P}<0.01$ vs. the control group. ${ }^{\#} \mathrm{P}<0.05,{ }^{\# \prime} \mathrm{P}<0.01$ between the indicated experimental groups. Data are presented as the mean \pm standard deviation $(n=3)$. GDNF, glial cell-derived neurotrophic factor; BDNF, brain-derived neurotrophic factor; CNTF, ciliary neurotrophic factor. which indicated that baicalin may stimulate the transcription of GDNF, BDNF and CNTF genes (Fig. 6). In addition, the present data suggested that SCs treated with $20 \mu \mathrm{M}$ baicalin exhibited the highest gene expression levels of GDNF, BDNF and CNTF genes.
Expression of $S 100 \beta$. Expression of $\mathrm{S} 100 \beta$ was detected by immunohistochemical staining. RSC96 SCs were treated with $0,5,10$ or $20 \mu \mathrm{M}$ of baicalin at different time points. As indicated in Fig. 7, the expression of $\mathrm{S} 100 \beta$ was upregulated when the concentration of baicalin increased and treatment 


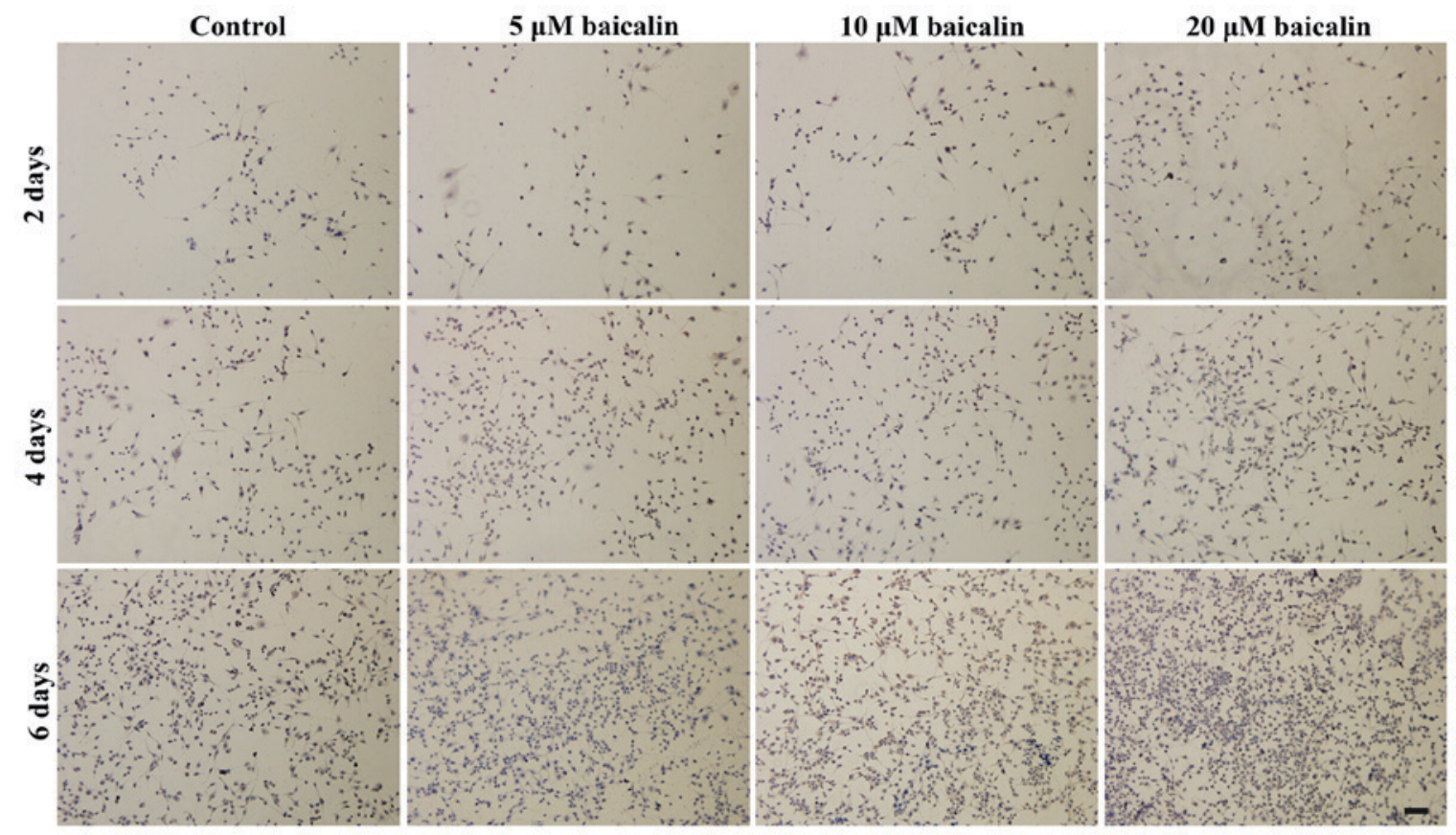

Figure 7. Immunohistochemical staining images revealed the presence of S100 $\beta$. RSC96 Schwann cells were cultured in vitro with 0 (control), 5,10 or $20 \mu \mathrm{M}$ of baicalin for 2, 4 and 6 days (magnification x100; scale bar, $200 \mu \mathrm{m}$ ).

with $20 \mu \mathrm{M}$ of baicalin resulted in the highest expression of S100 $\beta$ in SCs.

\section{Discussion}

The present study focused on the effect of baicalin on RSC96 $\mathrm{SCs}$ in vitro. The present findings indicated that baicalin significantly enhanced the viability of SCs. In addition, the expression of GDNF, BDNF and CNTF was significantly upregulated in the presence of $20 \mu \mathrm{M}$ baicalin. These findings revealed that baicalin is capable of enhancing SCs survival and function in vitro. This may corroborate that baicalin is a key component that is able to contribute to nerve repair by S. baicalensis (29). Moreover, the present study highlights the possibility of promoting nerve regeneration in cellular nerve grafts through baicalin-induced neurotrophin secretion in SCs.

Acceleration of the proliferation of nerve cells is important due to the slow axonal growth that is the cause of poor functional recovery, which may lead to prolonged denervation of end organs, raising the specter of permanent paralysis (30). In the present study, baicalin exhibited an effect in a dose-dependent manner on the viability of RSC96 SCs, whereby at the concentration of $20 \mu \mathrm{M}$, SCs exhibited the highest viability, as evidenced by cell viability assay and histological evaluation. S100, which is a SC marker (31), was elevated when SCs received baicalin treatment, as demonstrated by the increased protein expression levels of S100 in baicalin-treated cells when compared with the control, via immunohistochemical examination. Natural substrates, such as traditional medicinal herbs, are well-known for their relatively minor adverse effects (32). Extracts from $S$. baicalensis are considered to exhibit low cytotoxicity (33) and have neuroprotective properties (34). As one of the active components, baicalin has been reported to promote neuroprotective effects in rats $(25,35)$, which is in agreement with the findings of the present study.
Nerve growth factor and several neurotrophic factors have been reported to elicit stimulatory effects on specific neuronal populations $(36,37)$. They affect several vital aspects of regeneration, including axon growth, $\mathrm{SC}$ function and myelination (38). GDNF, BDNF and CNTF are several important neurotrophic factors that are important in the process of nerve cell regeneration (39). A previous study indicated that CNTF is able to enhance myelin formation and myelinate regenerating axons in the course of regrowth $(40,41)$. Furthermore, it has been suggested that BDNF is a necessary component for axon regeneration (42) and a small peptide mimetic of BDNF was demonstrated to promote peripheral myelination (43). Moreover, GDNF has been indicated to be beneficial to peripheral nerve regeneration and functional recovery in multiple experimental nerve injury models $(44,45)$. In addition, a recent study on autograft-based repair revealed that BDNF, GDNF and nerve growth factor showed considerable promise as these factors enhanced modality-specific axon regeneration in autografts (46). In the present study, when RSC96 SCs were incubated with $20 \mu \mathrm{M}$ baicalin, the gene expression levels of BDNF, CNTF and GDNF were significantly elevated, as determined by RT-qPCR. These findings suggest that baicalin likely promotes SCs viability and proliferation by stimulating neurotrophic factors, such as CNTF and GDNF.

S100 is associated with cell proliferation and differentiation (47). In the S100 protein family, S100B has been reported to be a potentially important factor contributing to neuronal development (48) and differentiation. A previous study has indicated that S100A4 is capable of stimulating neuronal differentiation in cultures of rat hippocampal neurons (49). In the present study, S100 protein expression levels were elevated by baicalin-treatment, as demonstrated by immunohistochemical examination. These findings suggest that baicalin may stimulate SC viability and differentiation via upregulation of S100. 
The present results showed that the different concentrations of baicalin (5 to $20 \mu \mathrm{M}$ ) affected the viability of RSC96 SCs, with $20 \mu \mathrm{M}$ having a significant effect. Among the chosen concentrations, treatment with $20 \mu \mathrm{M}$ of baicalin indicated the optimal cell viability and stimulated the most secretion of S100 in RSC96 SCs.

In conclusion, the present study corroborated that baicalin has a regulative effect on the viability of RSC96 SCs. Furthermore, the present findings suggest baicalin likely affects SC metabolism by modulating the expression of several neurotrophic factors, such as BDNF, GDNF and CDNF. To conclude, the present study suggests that baicalin may be a promising therapeutic agent for peripheral nerve regeneration.

\section{Acknowledgements}

The present study was financially supported by the National Natural Science Foundation of China (grant no. 81160221). This study was also supported by Research Center for Regenerative Medicine and Collaborative Innovation Center of Guangxi Biological Medicine.

\section{References}

1. Robinson LR: Traumatic injury to peripheral nerves. Muscle Nerve 23: 863-873, 2000

2. Evans GR: Peripheral nerve injury: A review and approach to tissue engineered constructs. Anat Rec 263: 396-404, 2001.

3. Griffin MF, Malahias M, Hindocha S and Khan WS: Peripheral nerve injury: Principles for repair and regeneration. Open Orthop J 8: 199-203, 2014

4. Schmidt CE and Leach JB: Neural tissue engineering: Strategies for repair and regeneration. Annu Rev Biomed Eng 5: 293-347, 2003

5. Moore AM, Kasukurthi R, Magill CK, Farhadi HF, Borschel GH and Mackinnon SE: Limitations of conduits in peripheral nerve repairs. Hand (N Y) 4: 180-186, 2009.

6. Pfister BJ, Gordon T, Loverde JR, Kochar AS, Mackinnon SE and Cullen DK: Biomedical engineering strategies for peripheral nerve repair: Surgical applications, state of the art, and future challenges. Crit Rev Biomed Eng 39: 81-124, 2011.

7. Ide C, Tohyama K, Yokota R, Nitatori T and Onodera S: Schwann cell basal lamina and nerve regeneration. Brain Res 288: 61-75, 1983.

8. Mudo G, Persson H, Timmusk T, Funakoshi H, Bindoni M and Belluardo N: Increased expression of trkB and trkC messenger RNAs in the rat forebrain after focal mechanical injury. Neuroscience 57: 901-912, 1993.

9. Toews AD, Barrett C and Morell P: Monocyte chemoattractant protein 1 is responsible for macrophage recruitment following injury to sciatic nerve. J Neurosci Res 53: 260-267, 1998.

10. Tofaris GK, Patterson PH, Jessen KR and Mirsky R: Denervated Schwann cells attract macrophages by secretion of leukemia inhibitory factor (LIF) and monocyte chemoattractant protein-1 in a process regulated by interleukin-6 and LIF. J Neurosci 22: 6696-6703, 2002.

11. Keilhoff G, Fansa H, Schneider W and Wolf G: In vivo predegeneration of peripheral nerves: An effective technique to obtain activated Schwann cells for nerve conduits. J Neurosci Methods 89: 17-24, 1999.

12. Terenghi G: Peripheral nerve regeneration and neurotrophic factors. J Anat 194: 1-14, 1999.

13. Faroni A, Rothwell SW, Grolla AA, Terenghi G, Magnaghi V and Verkhratsky A: Differentiation of adipose-derived stem cells into Schwann cell phenotype induces expression of $\mathrm{P} 2 \mathrm{X}$ receptors that control cell death. Cell Death Dis 4: e743, 2013.

14. Temporin K, Tanaka H, Kuroda Y, Okada K, Yachi K, Moritomo $\mathrm{H}$, Murase $\mathrm{T}$ and Yoshikawa $\mathrm{H}$ : Interleukin-1 beta promotes sensory nerve regeneration after sciatic nerve injury. Neurosci Lett 440: 130-133, 2008
15. Shen JL, Chen YS, Lin JY, Tien YC, Peng WH, Kuo CH, Tzang BS, Wang HL, Tsai FJ, Chou MC, et al: Neuron regeneration and proliferation effects of danshen and tanshinone IIA. Evid Based Complement Alternat Med 2011: 378907, 2011.

16. Park HL, Lee HS, Shin BC, Liu JP, Shang Q, Yamashita H and Lim B: Traditional medicine in china, Korea, and Japan: A brief introduction and comparison. Evid Based Complement Alternat Med 2012: 429103, 2012.

17. Normile D: Asian medicine. The new face of traditional Chinese medicine. Science 299: 188-190, 2003.

18. Haranaka R, Hasegawa R, Nakagawa S, Sakurai A, Satomi N and Haranaka K: Antitumor activity of combination therapy with traditional Chinese medicine and OK432 or MMC. J Biol Response Mod 7: 77-90, 1988.

19. Du Z, Wang K, Tao Y, Chen L and Qiu F: Purification of baicalin and wogonoside from Scutellaria baicalensis extracts by macroporous resin adsorption chromatography. J Chromatogr B Analyt Technol Biomed Life Sci 908: 143-149, 2012.

20. Kim AR, Kim SN, Jung IK, Kim HH, Park YH and Park WS: The inhibitory effect of Scutellaria baicalensis extract and its active compound, baicalin, on the translocation of the androgen receptor with implications for preventing androgenetic alopecia. Planta Med 80: 153-158, 2014.

21. Miao G, Zhao H, Guo K, Cheng J, Zhang S, Zhang X, Cai Z, Miao $\mathrm{H}$ and Shang Y: Mechanisms underlying attenuation of apoptosis of cortical neurons in the hypoxic brain by flavonoids from the stems and leaves of Scutellaria baicalensis Georgi. Neural Regen Res 9: 1592-1598, 2014

22. Li BQ, Fu T, Gong WH, Dunlop N, Kung H, Yan Y, Kang J and Wang JM: The flavonoid baicalin exhibits anti-inflammatory activity by binding to chemokines. Immunopharmacology 49: 295-306, 2000.

23. Hwang JM, Wang CJ, Chou FP, Tseng TH, Hsieh YS, Hsu JD and Chu CY: Protective effect of baicalin on tert-butyl hydroperoxide-induced rat hepatotoxicity. Arch Toxicol 79: 102-109, 2005.

24. Jung SH, Kang KD, Ji D, Fawcett RJ, Safa R, Kamalden TA and Osborne NN: The flavonoid baicalin counteracts ischemic and oxidative insults to retinal cells and lipid peroxidation to brain membranes. Neurochem Int 53: 325-337, 2008.

25. Tu XK, Yang WZ, Shi SS, Wang $\mathrm{CH}$ and Chen CM: Neuroprotective effect of baicalin in a rat model of permanent focal cerebral ischemia. Neurochem Res 34: 1626-1634, 2009.

26. Li Y, Zhuang P, Shen B, Zhang Y and Shen J: Baicalin promotes neuronal differentiation of neural stem/progenitor cells through modulating p-stat 3 and bHLH family protein expression. Brain Res 1429: 36-42, 2012.

27. Li M, Tsang KS, Choi ST, Li K, Shaw PC and Lau KF: Neuronal differentiation of C17.2 neural stem cells induced by a natural flavonoid, baicalin. Chembiochem 12: 449-456, 2011.

28. Livak KJ and Schmittgen TD: Analysis of relative gene expression data using real-time quantitative PCR and the 2(-Delta Delta C(T)) method. Methods 25: 402-408, 2001.

29. Heo HJ, Kim DO, Choi SJ, Shin DH and Lee CY: Potent Inhibitory effect of flavonoids in Scutellaria baicalensis on amyloid beta protein-induced neurotoxicity. J Agric Food Chem 52: 4128-4132, 2004

30. Chang YM, Kuo WH, Lai TY, Shih YT, Tsai FJ, Tsai CH, Shu WT, Chen YY, Chen YS, Kuo WW and Huang CY: RSC96 Schwann cell proliferation and survival induced by dilong through PI3K/Akt signaling mediated by IGF-I. Evid Based Complement Alternat Med 2011: 216148, 2011.

31. Liu Z, Jin YQ, Chen L, Wang Y, Yang X, Cheng J, Wu W, Qi Z and Shen Z: Specific marker expression and cell state of Schwann cells during culture in vitro. PLoS One 10: e0123278, 2015.

32. Barbisan LF, Miyamoto M, Scolastici C, Salvadori DM, Ribeiro LR, Eira AF and de Camargo JL: Influence of aqueous extract of Agaricus blazei on rat liver toxicity induced by different doses of diethylnitrosamine. J Ethnopharmacol 83: 25-32, 2002.

33. Burnett BP, Silva S, Mesches MH, Wilson S and Jia Q: Safety evaluation of a combination, defined extract of Scutellaria baicalensis and Acacia catechu. J Food Biochem 31: 797-825, 2007.

34. Kim YO, Leem K, Park J, Lee P, Ahn DK, Lee BC, Park HK, Suk K, Kim SY and Kim H: Cytoprotective effect of Scutellaria baicalensis in CA1 hippocampal neurons of rats after global cerebral ischemia. J Ethnopharmacol 77: 183-188, 2001.

35. Cao Y, Li G, Wang YF, Fan ZK, Yu DS, Wang ZD and Bi YL: Neuroprotective effect of baicalin on compression spinal cord injury in rats. Brain Res 1357: 115-123, 2010. 
36. Aloe L, Rocco ML, Bianchi P and Manni L: Nerve growth factor: From the early discoveries to the potential clinical use. J Transl Med 10: 239, 2012.

37. Bothwell M: NGF, BDNF, NT3 and NT4. Handb Exp Pharmacol 220: 3-15, 2014

38. Klimaschewski L, Hausott B and Angelov DN: The pros and cons of growth factors and cytokines in peripheral axon regeneration. Int Rev Neurobiol 108: 137-171, 2013.

39. Gordon T: The role of neurotrophic factors in nerve regeneration. Neurosurg Focus 26: E3, 2009.

40. Stankoff B, Aigrot MS, Noël F, Wattilliaux A, Zalc B and Lubetzki C: Ciliary neurotrophic factor (CNTF) enhances myelin formation: A novel role for CNTF and CNTF-related molecules. J Neurosci 22: 9221-9227, 2002.

41. Vernerey J, Macchi M, Magalon K, Cayre M and Durbec P: Ciliary neurotrophic factor controls progenitor migration during remyelination in the adult rodent brain. J Neurosci 33: 3240-3250, 2013.

42. Wilhelm JC, Xu M, Cucoranu D, Chmielewski S, Holmes T, Lau KS, Bassell GJ and English AW: Cooperative roles of BDNF expression in neurons and Schwann cells are modulated by exercise to facilitate nerve regeneration. J Neurosci 32: 5002-5009, 2012.

43. Xiao J, Hughes RA, Lim JY, Wong AW, Ivanusic JJ, Ferner AH, Kilpatrick TJ and Murray SS: A small peptide mimetic of brain-derived neurotrophic factor promotes peripheral myelination. J Neurochem 125: 386-398, 2013.
44. Tannemaat MR, Eggers R, Hendriks WT, de Ruiter GC, van Heerikhuize JJ, Pool CW, Malessy MJ, Boer GJ and Verhaagen J: Differential effects of lentiviral vector-mediated overexpression of nerve growth factor and glial cell line-derived neurotrophic factor on regenerating sensory and motor axons in the transected peripheral nerve. Eur J Neurosci 28: 1467-1479, 2008.

45. Anitha M, Gondha C, Sutliff R, Parsadanian A, Mwangi S, Sitaraman SV and Srinivasan S: GDNF rescues hyperglycemia-induced diabetic enteric neuropathy through activation of the PI3K/Akt pathway. J Clin Invest 116: 344-356, 2006.

46. Hoyng SA, De Winter F, Gnavi S, de Boer R, Boon LI, Korvers LM, Tannemaat MR, Malessy MJ and Verhaagen J: A comparative morphological, electrophysiological and functional analysis of axon regeneration through peripheral nerve autografts genetically modified to overexpress BDNF, CNTF, GDNF, NGF, NT3 or VEGF. Exp Neurol 261: 578-593, 2014.

47. Donato R, Cannon BR, Sorci G, Riuzzi F, Hsu K, Weber DJ and Geczy CL: Functions of S100 proteins. Curr Mol Med 13: 24-57, 2013.

48. Donato R: Intracellular and extracellular roles of S100 proteins. Microsc Res Tech 60: 540-551, 2003.

49. Novitskaya V, Grigorian M, Kriajevska M, Tarabykina S, Bronstein I, Berezin V, Bock E and Lukanidin E: Oligomeric forms of the metastasis-related Mts1 (S100A4) protein stimulate neuronal differentiation in cultures of rat hippocampal neurons. J Biol Chem 275: 41278-41286, 2000. 